\title{
Solubility of Gliclazide in Transcutol + Water Co-solvent Mixtures at (298.15 to 333.15) $K$
}

\author{
Nazrul Haq, ${ }^{\text {a,b }}$ Fars K. Alanazi, ${ }^{\text {b,c }}$ Ibrahim A. Alsarra, ${ }^{\text {a,b }}$ and Faiyaz Shakeel ${ }^{\mathrm{a}, \mathrm{b}, *}$ \\ ${ }^{a}$ Research Center, College of Science, King Saud University, Riyadh 11451, Saudi Arabia \\ ${ }^{\mathrm{b}}$ Department of Pharmaceutics, College of Pharmacy, King Saud University, \\ P.O. Box 2457, Riyadh 11451, Saudi Arabia \\ 'Kayyali Chair for Pharmaceutical Industry, Department of Pharmaceutics, College of Pharmacy, King Saud University, \\ P.O. Box 2457, Riyadh 11451, Saudi Arabia
}

\begin{abstract}
The aim of present investigation was to determine the mole fraction solubility of a poorly water soluble antidiabetic drug gliclazide (GLZ) in mono-solvents and various Transcutol + water co-solvent mixtures at (298.15 to 333.15 ) K. The experimental solubility of GLZ was measured by shake flask method and resulting data was correlated with the modified Apelblat model at each temperature studied. Good correlation was observed between the experimental data of GLZ and calculated one with absolute relative deviation in the range of $(0.050$ to 5.680$) \%$. The correlation coefficients were observed in the range of 0.9966 to 0.9995 which indicated good fitting of experimental solubility data. The lowest mole fraction solubility of GLZ was observed in pure water $\left(1.9 \times 10^{-6}\right.$ at $\left.298.15 \mathrm{~K}\right)$ whereas the highest one was observed in pure Transcutol $\left(11.9 \times 10^{-3}\right.$ at $\left.298.15 \mathrm{~K}\right)$. The enthalpies and entropies for GLZ dissolution were observed as positive values in the range of (15.742 to 40.551$) \mathrm{kJ} \mathrm{mol}^{-1}$ and (52.801 to 121.721) $\mathrm{J} \mathrm{mol}^{-1} \mathrm{~K}^{-1}$, respectively in all sample matrices. These results of thermodynamic parameters indicated that the dissolution of GLZ is endothermic and an entropy-driven process. Based on current solubility data, GLZ was considered as practically insoluble (poorly soluble) in pure water and soluble in Transcutol. These preliminary studies indicated that Transcutol could be used as a co-solvent for solubility enhancement of GLZ which could help in preformulation studies and formulation development of GLZ.
\end{abstract}

Keywords: gliclazide, modified Apelblat model, solubility, thermodynamics, Transcutol

\section{INTRODUCTION}

The IUPAC name of gliclazide (GLZ) is $1-(3,3 a, 4,5,6$, 6a-hexahydro- $1 H$-cyclopenta[c]pyrrol-2-yl)-3-(4-methylphenyl) sulfonylurea (Figure 1, molecular formula: $\mathrm{C}_{15} \mathrm{H}_{21} \mathrm{~N}_{3} \mathrm{O}_{3} \mathrm{~S}$, molecular mass: $323.411 \mathrm{~g} \mathrm{~mol}^{-1}$, CAS registry number: $21187-98-4) .{ }^{1,2}$ It is a second generation hypoglycemic agent which is prescribed in the treatment of type 2 diabetes mellitus. ${ }^{1-4}$ It is very poorly soluble drug according to the biopharmaceutical classification system (BCS) of drugs (BCS class II) due to which its dissolution is poor. ${ }^{2,4}$ Poor solubility and dissolution often resulted in poor in vivo absorption of such drugs. ${ }^{4}$ Poor solubility and poor dissolution are the main obstacles for formulation development of GLZ. ${ }^{1,2,4}$ The aqueous solubility of GLZ at 25 and $37^{\circ} \mathrm{C}$ has been reported as $<40$ and $55 \mu \mathrm{g} \mathrm{ml}^{-1}$, respectively. ${ }^{3,5}$ Various approaches such as surfactants, ${ }^{5}$ solid dispersions, ${ }^{1,4,6-10}$ micronization, ${ }^{11,12}$ ordered mixing, ${ }^{2}$ co-grinding ${ }^{13}$ and cyclodextrins complexation ${ }^{14}$ have been applied to enhance solubility and dissolution rate of GLZ. Co-solvent approach has also been applied to enhance aqueous solubility of seven poorly soluble antidiabetic drugs including GLZ. ${ }^{3}$ Co-solvent technique is error free approach which is usually applied for solubilization as well as stabilization of drugs/pharmaceuticals in aqueous solutions. ${ }^{15,16}$ Solubility is one of the important<smiles>Cc1ccc(S(=O)(=O)NC(=O)NN2CC3CCCC3C2)cc1</smiles>

Figure 1. Molecular structure of GLZ

\footnotetext{
* Author to whom correspondence should be addressed. (E-mail: faiyazs@fastmail.fm)
} 
physicochemical properties of the drugs because of its wide range of applications such as drug crystallization/purification, drug dissolution/permeation, prefo rmulation studies and formulation development. ${ }^{15-18}$ Therefore, solubility data of poorly soluble drugs must be determined in wide range of temperatures to get complete information about physicochemical characterization of drugs. ${ }^{19}$ The IUPAC name of Transcutol is diethylene glycol monoethyl ether which has been investigated as a cosurfactant in the preparation and characterization of several lipid based formulations such as nanoemulsions/microemulsions and self-nanoemulsifying (SNEDDS)/self-microemulsifying (SMEDDS) drug delivery systems. ${ }^{17,20-22}$ These lipid based formulations (nanoemulsions/microemulsions and SNEDDS/SMEDDS) are known to enhance solubility/dissolution and bioavailability of poorly soluble drugs. ${ }^{20-25}$ In spite of great solubilizing and stabilizing capacity of Transcutol, it has never been investigated as a co-solvent to enhance solubility of GLZ in water-co-solvent mixtures in literature so far. Therefore, the aim of present investigation was to determine the mole fraction solubility of GLZ in monosolvents (pure water and pure Transcutol) as well as in various Transcutol-water co-solvent mixtures at temperature range from (298.15 to 333.15 ) K. The experimental mole fraction solubility data was also correlated with the modified Apelblat model. These preliminary studies could be very useful in the development of lipid based formulations of GLZ.

\section{EXPERIMENTAL}

\section{Materials}

Gliclazide (mass fraction purity of 0.986) was purchased from Sigma Aldrich (St. Louis, MO). Tarnscutol-HP (mass fraction purity of 0.9998) was kindly gifted from Gattefosse (Lyon, France). Distilled water was obtained from distillation unit in our laboratory. All other chemicals used were of analytical grade. The general properties of these materials are presented in Table 1.

\section{Measurement of GLZ Solubility}

The mole fraction solubility of GLZ against mass fraction of Transcutol ( $w=0.0$ to 1.0) in Transcutol-water co-solvent mixtures was determined by shake flask method at various temperatures (298.15 to 333.15) $\mathrm{K} .^{15,17,18}$ The excess amount of GLZ was added in $5 \mathrm{~g}$ of each co-solvents mixture including pure water $(w=0.0)$ and pure Transcutol $(w=1.0)$ in $10 \mathrm{ml}$ capacity vials in triplicate to obtain drug suspensions. Each vial was tightly closed. Drug suspension of each co-solvent mixture was then kept in an isothermal mechanical shaker bath (Julabo, PA) at shaking speed of $100 \mathrm{rpm}$ for $72 \mathrm{~h}$ to reach the equilibrium. These experiments were carried out at different temperatures (298.15 to 333.15$) \mathrm{K}$. After the period of $72 \mathrm{~h}$, all drug suspensions were taken out from the shaker bath and allowed to settle drug particles for the period of $2 \mathrm{~h}$ at the bottom of the vials. ${ }^{18,26}$ All the drug suspensions were filtered using $0.45 \mu \mathrm{m}$ filter paper, supernatant from each sample was taken and diluted 1000 times with respective solvent/cosolvent mixture and subjected for analysis of GLZ content at the wavelength of $227 \mathrm{~nm}$ using UV-Visible spectrophotometer (SP1900, Axiom, Germany). ${ }^{1,7}$ The proposed analytical method was found to be linear in the range of (2 to 50) $\mu \mathrm{g} / \mathrm{g}$ with correlation coefficient $\left(R^{2}\right)$ of 0.999 . The standard uncertainty for the temperatures $u(T)$ was observed as $\pm 0.03 \mathrm{~K}$. However, the relative standard uncertainty in solubility $u_{r}\left(x_{\mathrm{e}}\right)$ was found to be $0.97 \%$. The experimental mole fraction solubility $\left(x_{\mathrm{e}}\right)$ of GLZ was calculated using equation $1:^{15,17,18,26}$

$$
x_{\mathrm{e}}=\frac{m_{1} / M_{1}}{m_{1} / M_{1}+m_{2} / M_{2}+m_{3} / M_{3}}
$$

where $m_{1}, m_{2}$, and $m_{3}$ represent the masses (expressed in g) of GLZ (solute), Transcutol, and water, respectively. $M_{1}, M_{2}$, and $M_{3}$ represent the molecular masses (expressed in $\mathrm{g} \mathrm{mol}^{-1}$ ) of GLZ, Transcutol, and water, respectively.

\section{RESULTS AND DISCUSSION}

\section{Solubility Data of GLZ}

The experimental mole fraction solubility data of GLZ in mono-solvents (pure Transcutol and pure water) and Transcutol-water co-solvent mixtures at various temperatures are listed in Table 2. The solubility of GLZ was found to be increased exponentially with temperature in all sample matrices. The mole fraction solubility of GLZ was found to be lowest in pure water $\left(1.9 \times 10^{-6}\right.$ at

Table 1. General properties of GLZ, Transcutol and water

\begin{tabular}{cccccc}
\hline Materials & Molecular formula & $M / \mathrm{g} \mathrm{mol}^{-1}$ & $\mathrm{D} / \mathrm{g} \mathrm{ml}^{-1}$ & Purity / \% & CAS No. \\
\hline GLZ & $\mathrm{C}_{15} \mathrm{H}_{21} \mathrm{~N}_{3} \mathrm{O}_{3} \mathrm{~S}$ & 323.411 & 1.340 & 98.60 & $21187-98-4$ \\
Transcutol & $\mathrm{C}_{6} \mathrm{H}_{14} \mathrm{O}_{3}$ & 134.170 & 0.990 & 99.98 & $111-90-0$ \\
Water & $\mathrm{H}_{2} \mathrm{O}$ & 18.015 & 1.000 & 100.00 & $7732-18-5$ \\
\hline
\end{tabular}


Table 2. Experimental mole fraction solubilities $\left(x_{\mathrm{e}}\right)$ of crystalline GLZ against mass fraction of Transcutol $(w)$ in various Transcutol + water co-solvent mixtures in the absence of solute at temperatures $T=(298.15$ to 333.15$) \mathrm{K}$ and pressure $p=0.1 \mathrm{MPa}$ (the standard uncertainty for the temperatures $u(T)$ is $\pm 0.03 \mathrm{~K}$, the relative standard uncertainty in solubility $u_{r}\left(x_{\mathrm{e}}\right)$ is $\left.0.97 \%\right)$

\begin{tabular}{ccccccccc}
\hline \multirow{2}{*}{$w$} & \multicolumn{7}{c}{$x_{\mathrm{e}}$} \\
\cline { 2 - 8 } & $T=298.15 \mathrm{~K}$ & $T=303.15 \mathrm{~K}$ & $T=308.15 \mathrm{~K}$ & $T=313.15 \mathrm{~K}$ & $T=318.15 \mathrm{~K}$ & $T=323.15 \mathrm{~K}$ & $T=328.15 \mathrm{~K}$ & $T=333.15 \mathrm{~K}$ \\
\hline 0.0 & $1.95 \times 10^{-6}$ & $2.34 \times 10^{-6}$ & $2.84 \times 10^{-6}$ & $3.51 \times 10^{-6}$ & $4.23 \times 10^{-6}$ & $5.07 \times 10^{-6}$ & $6.02 \times 10^{-6}$ & $7.02 \times 10^{-6}$ \\
0.1 & $1.21 \times 10^{-4}$ & $1.52 \times 10^{-4}$ & $1.95 \times 10^{-4}$ & $2.63 \times 10^{-4}$ & $3.32 \times 10^{-4}$ & $4.08 \times 10^{-4}$ & $5.01 \times 10^{-4}$ & $6.08 \times 10^{-4}$ \\
0.2 & $2.55 \times 10^{-4}$ & $3.09 \times 10^{-4}$ & $3.63 \times 10^{-4}$ & $4.30 \times 10^{-4}$ & $4.98 \times 10^{-4}$ & $5.79 \times 10^{-4}$ & $6.79 \times 10^{-4}$ & $7.87 \times 10^{-4}$ \\
0.3 & $3.91 \times 10^{-4}$ & $4.66 \times 10^{-4}$ & $5.56 \times 10^{-4}$ & $6.61 \times 10^{-4}$ & $7.81 \times 10^{-4}$ & $9.09 \times 10^{-4}$ & $1.05 \times 10^{-3}$ & $1.20 \times 10^{-3}$ \\
0.4 & $6.30 \times 10^{-4}$ & $7.15 \times 10^{-4}$ & $8.34 \times 10^{-4}$ & $9.53 \times 10^{-4}$ & $1.08 \times 10^{-3}$ & $1.20 \times 10^{-3}$ & $1.33 \times 10^{-3}$ & $1.49 \times 10^{-3}$ \\
0.5 & $1.50 \times 10^{-3}$ & $1.76 \times 10^{-5}$ & $2.05 \times 10^{-3}$ & $2.31 \times 10^{-3}$ & $2.62 \times 10^{-3}$ & $2.95 \times 10^{-3}$ & $3.33 \times 10^{-3}$ & $3.65 \times 10^{-3}$ \\
0.6 & $1.89 \times 10^{-3}$ & $2.10 \times 10^{-3}$ & $2.46 \times 10^{-3}$ & $2.86 \times 10^{-3}$ & $3.26 \times 10^{-3}$ & $3.78 \times 10^{-3}$ & $4.25 \times 10^{-3}$ & $4.63 \times 10^{-3}$ \\
0.7 & $2.53 \times 10^{-3}$ & $2.90 \times 10^{-3}$ & $3.22 \times 10^{-4}$ & $3.77 \times 10^{-3}$ & $4.19 \times 10^{-3}$ & $4.79 \times 10^{-3}$ & $5.38 \times 10^{-3}$ & $6.09 \times 10^{-3}$ \\
0.8 & $3.79 \times 10^{-3}$ & $4.25 \times 10^{-3}$ & $4.70 \times 10^{-3}$ & $5.47 \times 10^{-3}$ & $6.21 \times 10^{-3}$ & $6.80 \times 10^{-3}$ & $7.55 \times 10^{-3}$ & $8.53 \times 10^{-3}$ \\
0.9 & $6.21 \times 10^{-3}$ & $6.86 \times 10^{-3}$ & $7.65 \times 10^{-3}$ & $8.62 \times 10^{-3}$ & $9.64 \times 10^{-3}$ & $1.05 \times 10^{-2}$ & $1.15 \times 10^{-2}$ & $1.27 \times 10^{-2}$ \\
1.0 & $1.19 \times 10^{-2}$ & $1.33 \times 10^{-2}$ & $1.46 \times 10^{-2}$ & $1.62 \times 10^{-2}$ & $1.82 \times 10^{-2}$ & $2.06 \times 10^{-2}$ & $2.32 \times 10^{-2}$ & $2.62 \times 10^{-2}$ \\
\hline
\end{tabular}

298.15 K) whereas the highest one was observed in pure Transcutol $\left(11.9 \times 10^{-3}\right.$ at $\left.298.15 \mathrm{~K}\right)$ at each temperature studied (Table 2). However, the mole fraction solubility of GLZ in pure Transcutol was significantly higher than pure water at each temperature studied. The impact of mass fraction of Transcutol on mole fraction solubility of GLZ at various temperatures is presented in Figure 2. The mole fraction solubility of GLZ was found to be increased with increase in mass fraction of Transcutol in Transcutol-water co-solvent mixtures at each temperature studied. This was probably due to the reduced polarities in co-solvent mixtures as compared to pure water which is a highly polar solvent. ${ }^{27}$ The lowest solubility of GLZ in pure water was also due to its highest polarity. ${ }^{28}$ It is also very well reported in literature that the solubility of drug/solute molecules could be enhanced by reducing the polarity of solvents/co-solvent mixtures. ${ }^{29}$ Therefore, increased solubility of GLZ in co-solvent mixtures was probably due to reduced polarities. $^{27-29}$ The solubility data of GLZ in present study was in agreement with previous report of polarities. The highest mole fraction solubility of GLZ in pure Transcutol was probably due to the lowest polarity of Transcutol. The mole fraction solubility of GLZ in pure water at 298.15 and $310.15 \mathrm{~K}$ has been reported as $<2.23 \times 10^{-6}$ and $3.06 \times 10^{-6}$, respectively. ${ }^{3,5}$ However, in present study the mole fraction solubility of GLZ in pure water at 298.15 and $308.15 \mathrm{~K}$ was observed as $1.9 \times 10^{-6}$ and $2.84 \times 10^{-6}$, respectively which were very close to reported values (Table 2). Based on these results, GLZ has been considered as practically insoluble (poorly soluble) in pure water and soluble in pure Transcutol. Therefore, Transcutol could be utilized as a physiologically compatible co-solvent in formulation development of GLZ in future studies.

\section{Thermodynamic Modeling of GLZ Solubility}

In present study, the experimental solubility data of GLZ was correlated with the modified Apelblat model because it is commonly used model applied for both polar as well as for nonpolar systems. ${ }^{15,18,26}$ According to this model, the mole fraction solubility of solute is temperature-dependent which can be represented by equation 2 to describe solid-liquid equilibrium: ${ }^{18,30}$

$$
\ln x=A+\frac{B}{T}+C \ln (T)
$$

Where, $x$ represents the calculated/Apelblat solubility of GLZ. $T$ represents the absolute temperature (in $\mathrm{K}$ ) and parameters $A, B$, and $C$ are adjustable model parameters.

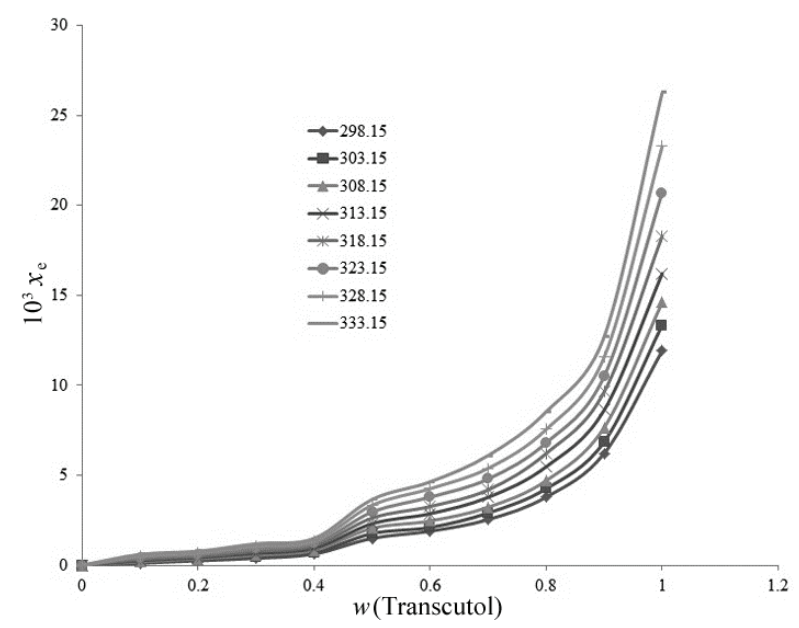

Figure 2. Effect of mass fraction of Transcutol on mole fraction solubility $\left(x_{\mathrm{e}}\right)$ of GLZ at various temperatures. 

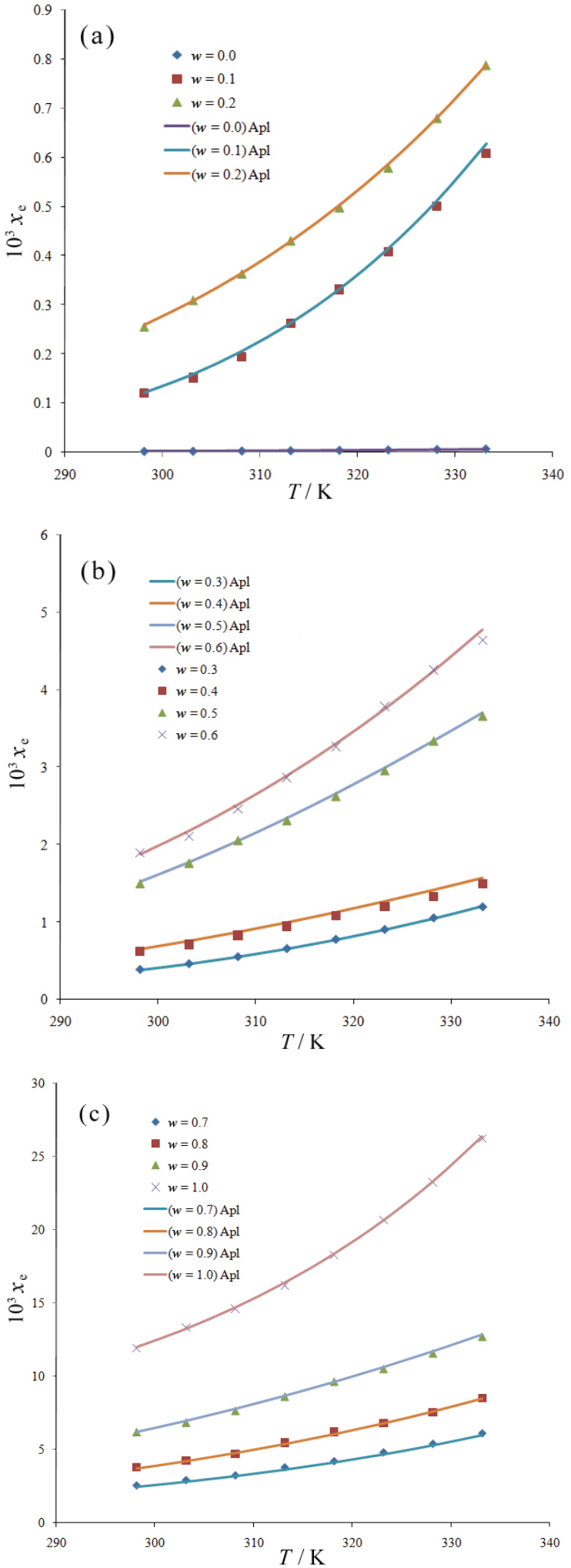

Figure 3. Correlation and curve fitting of experimental mole fraction solubilities $\left(x_{\mathrm{e}}\right)$ of GLZ with the modified Apelblat solubilities in various Transcutol + water co-solvent mixtures from (298.15 to 313.15) K. Lower solubility curves (a), middle solubility curves (b), and higher solubility curves (c).
These parameters $(A, B$, and $C$ ) were calculated by nonlinear multivariate regression analysis of experimental solubility data using equation 2 . The calculated/Apelblat solubilities $(x)$ were then calculated with the help of model parameters $A, B$, and $C$. The correlation and curve fitting between $x_{\mathrm{e}}$ and $x$ in various Transcutol + water mixtures from (298.15 to 333.15$) K$ is presented Figures $3 \mathrm{a}$ to $3 \mathrm{c}$.

The root mean square deviations (RMSD) between $x_{\mathrm{e}}$ and $x$ for crystalline GLZ were calculated using equation 2 .

$$
R M S D=\left[\frac{1}{N} \sum_{i=1}^{N}\left(\frac{x-x_{\mathrm{e}}}{x_{\mathrm{e}}}\right)^{2}\right]^{\frac{1}{2}}
$$

Where, $N$ is the number of data points which were 8 in the preset experiment. The values of regressed parameters $A, B$, and $C, R^{2}, R M S D$ and standard errors $(S E)$ of GLZ in various Transcutol + water co-solvent mixtures are listed in Table 3. The $R M S D$ values for GLZ were observed in the range of ( 0.53 to 5.23$) \%$ in all cosolvent mixtures investigated (Table 3 ). However, the values of $S E$ were observed in the range of 0.005 to .023 in all co-solvent mixtures. The RMSD value of GLZ was found to be lowest at $w=0.3$ of Transcutol in Transcutol + water mixture $(0.53 \%)$. However, the highest one was at $w=0.4$ of Transcutol in Transcutol + water mixture $(5.23 \%)$. The $R^{2}$ value for GLZ in pure water and pure Transcutol was found to be of 0.999 and 0.996 , respectively (Table 3 ). The $R^{2}$ values for GLZ in other co-solvent mixtures were observed in the range of 0.996 to 0.999 . Overall, the data of RMSD, SE and $R^{2}$ in all sample matrices indicated the good fitting of experimental data with the modified Apelblat model.

\section{Thermodynamic Parameters for GLZ Dissolution}

According to the thermodynamic principles, the dissolution of GLZ (solute) into a liquid can be expressed as: ${ }^{17,18,31}$

\section{Solid + liquid $=$ solid-liquid at the equilibrium}

The standard molar enthalpy $\left(\Delta H^{\ominus}\right)$ and entropy $\left(\Delta S^{\ominus}\right)$ of GLZ dissolution can be calculated using equations 4 and 5 , respectively:

$$
\begin{aligned}
& \Delta H^{\ominus}=R T\left(C-\frac{B}{T}\right) \\
& \Delta S^{\ominus}=R\left(C-\frac{B}{T}\right)
\end{aligned}
$$


Table 3. Apelblat parameters $(A, B$, and $C)$, correlation coefficients $\left(R^{2}\right)$, root mean square deviations $(R M S D)$ and standard errors $(S E)$ for crystalline GLZ in Transcutol + water co-solvent mixtures of various mass fraction of Transcutol $(w)$

\begin{tabular}{ccccccc}
\hline$w$ & $A$ & $B$ & $C$ & $R^{2}$ & $R M S D / \%$ & $S E$ \\
\hline 0.0 & 5.35 & -3981.92 & -0.90 & 0.999 & 0.98 & 0.011 \\
0.1 & 119.73 & -9930.77 & -16.75 & 0.997 & 3.07 & 0.023 \\
0.2 & -4.67 & -2830.89 & 1.03 & 0.999 & 0.94 & 0.008 \\
0.3 & 63.41 & -6043.31 & -8.95 & 0.998 & 0.53 & 0.005 \\
0.4 & 96.95 & -6951.20 & -14.21 & 0.997 & 5.23 & 0.009 \\
0.5 & 120.11 & -8034.21 & -17.49 & 0.996 & 1.09 & 0.007 \\
0.6 & 32.41 & -4043.36 & -4.41 & 0.996 & 2.02 & 0.020 \\
0.7 & -72.49 & 1003.92 & 11.08 & 0.999 & 1.93 & 0.010 \\
0.8 & -26.94 & -954.96 & 4.31 & 0.997 & 1.30 & 0.015 \\
0.9 & 11.27 & -2495.13 & -1.40 & 0.998 & 1.47 & 0.008 \\
1.0 & -203.26 & 7386.94 & 30.55 & 0.996 & 0.66 & 0.005 \\
\hline
\end{tabular}

Where, $R$ and $T$ represent the universal gas constant and absolute temperature (expressed in K), respectively. The $\Delta H^{\ominus}$ values for GLZ dissolution in mono-solvents (water and Transcutol) ranged from (30.60 to 30.86$) \mathrm{kJ} \mathrm{mol}^{-1}$ and (14.31 to 23.20$) \mathrm{kJ} \mathrm{mol}^{-1}$, respectively at various temperatures. However, the $\Delta H^{\theta}$ values for GLZ dissolution in co-solvent mixtures were observed in the range of $(16.86$ to 41.04$) \mathrm{kJ} \mathrm{mol}^{-1}$. The $\Delta H^{\ominus}$ values for GLZ dissolution in pure Transcutol were significantly reduced as compared to pure water. These results indicated that relatively low energy is required for solubilization of GLZ in pure Transcutol as compared to pure water. Because of positive values of $\Delta H^{\ominus}$ in mono-solvents and co-solvent mixtures, the dissolution of GLZ was assumed to be endothermic. Moreover, the $\Delta S^{\ominus}$ values for GLZ dissolution in monosolvents and co-solvent mixtures were also observed as positive values (48.00 to 103.51 ) $\mathrm{J} \mathrm{mol}^{-1} \mathrm{~K}^{-1}$ at each temperature studied which also indicated that GLZ dissolution is an endothermic and an entropy-driven process.

\section{CONCLUSION}

In the present study, the mole fraction solubility of poorly soluble drug GLZ in pure water, pure Transcutol and various co-solvent mixtures at temperature range from (298.15 to 333.15$) \mathrm{K}$ was determined. The mole fraction solubility of GLZ was found to be increase exponentially with temperature in mono-solvents and co-solvent mixtures. The solubility of GLZ was significantly enhanced in pure Transcutol and co-solvent mixtures as compared to pure water. The experimental data of GLZ was correlated and fitted well with the modified Apelblat model in mono-solvents and co-solvent mixtures. Based solubility data of this study, GLZ has been considered as soluble in pure Transcutol and practically insoluble in pure water. These studies indicated that Transcutol could be used as a co-solvent in formulation development of GLZ.
Conflict of Interest. - The authors report no conflict of interest. The authors alone are responsible for the content and writing of the paper.

Acknowledgements. The authors would like to extend their appreciation to the Deanship of Scientific Research, College of Science Research Center, King Saud University, Riyadh, Saudi Arabia for supporting this project.

\section{REFERENCES}

1. S. Biswal, J. Sahoo, P. N. Murthy, R. P. Giradkar, and J. G. Avari, AAPS Pharm. Sci. Tech. 9 (2008) 563-570.

2. V. A. Saharan, and P. K. Choudhury, Acta Pharm. 61 (2011) 323-334.

3. N. Seedher and M. Kanojia, Pharm. Develop. Technol. 14 (2009) 185-192.

4. G. V. Shavi, A. R. Kumar, Y. N. Usha, K. Armugam, O. P. Ranjan, K. Ginjupalli, S. Pandey, and N. Udupa, Int. J. Drug Deliv. 2 (2010) 49-57.

5. H. Allaboun, K. A. Alkhamis, and W. Y. Al-Momani, Eur. J. Pharm. Sci. 19 (2003) 231-236.

6. S. Asyarie, and H. Rachmawati, PDA J. Pharm. Sci. Technol. 61 (2007) 400-410

7. S. Biswal, J. Sahoo, and P. N. Murthy, Tropical J. Pharm. Res. 8 (2009) 717-724.

8. M. P. Patil, and N. J. Gaikwad, Acta Pharm. 59 (2009) 57-65.

9. R. Panigrahi, S. P. Behera, and P. N. Murthy, Int. J. Pharm. Tech. Res. 3 (2011) 1118-1124.

10. S. R. Devireddy, and P. R. Veerareddy, Int. J. Drug Deliv. 4 (2012) 455-461.

11. R. Talari, A. Nokhodchi, S. A. Mostafavi, and J. Varshosaz, J. Pharm. Pharm. Sci. 12 (2009) 250-265.

12. R. Talari, J. Varshosaz, S. A. Mostafavi, and A. Nokhodchi, AAPS Pharm. Sci. Tech. 11 (2010) 786-792.

13. M. Barzegar-Jalalia, H. Valizadeha, M. R. S. Shadbada, K. Adibkiaa, G. Mohammadia, A. Farahania, Z. Arasha, and A. Nokhodchi, Powder Technol. 197 (2010) 150-158.

14. Y. K. Lo, C. J. Chen, T. R. Tsai, and T. M. Cham, Drug Develop. Ind. Pharm. 33 (2007) 301-309.

15. F. Shakeel, F. K. Alanazi, I. A. Alsarra, and N. Haq, Pharm. Develop. Technol. 19 (2014) 702-707.

16. J. Soleymani, D. Djozan, F. Martinez, and A. Jouyban, J. Mol. Liq. 182 (2013) 91-94. 
17. F. Shakeel, N. Haq, F. K. Alanazi, and I. A. Alsarra, J. Mol. Liq. 191 (2014) 68-72.

18. N. Sunsandee, M. Hronec, M. Stolcova, N. Leepipatpiboon, and U. Pancharoen, J. Mol. Liq. 180 (2013) 252-259.

19. J. A. Jimenez, and F. Martinez, J. Braz. Chem. Soc. 17 (2006) $125-134$.

20. S. Shafiq, F. Shakeel, S. Talegaonkar, F. J. Ahmad, R. K. Khar, and M. Ali, Eur. J. Pharm. Biopharm. 66 (2007) 227-243.

21. F. Shakeel, S. Baboota, A. Ahuja, J. Ali, and S. Shafiq, J. Drug Target. 16 (2008) 733-740.

22. F. Shakeel, N. Haq, M. Elbadry, F. K. Alanazi, and I. A. Alsarra, J. Mol. Liq. 180 (2013) 89-94.

23. F. Shakeel, W. Ramadan, M. S. Faisal, M. Rizwan, M. Faiyazuddin, G. Mustafa, and S. Shafiq, Curr. Nanosci. 6 (2010) 184-198.
24. F. Shakeel, S. Shafiq, N. Haq, F. K. Alanazi, and I. A. Alsarra, Expert Opin. Drug Deliv. 9 (2012) 953-974.

25. F. Shakeel, N. Haq, F. K. Alanazi, and I. A. Alsarra, J. Mol. Liq. 182 (2013) 57-63.

26. E. A. Cantillo, D. R. Delgado, and F. Martinez, J. Mol. Liq. 181 (2013) 62-67.

27. M. Faraji, A. Farajtabar, and F. Gharib, J. Appl. Chem. Res. 9 (2009) 7-12.

28. C. S. Mali, S. D. Chavan, K. S. Kanse, A. C. Kumbharkhane, and S. C. Mehrotra, Ind. J. Pure Appl. Phys. 45 (2007) 476-481.

29. J. Chen, S. K. Spear, J. G. Huddleston, and R. D. Rogers, Green Chem. 7 (2005) 64-82.

30. A. Apelblat and E. Manzurola, J. Chem. Thermodyn. 31 (1999) 85-91.

31. C. L. Zhang, F. Zhao, and Y. Wang, J. Mol. Liq. 159 (2011) 170-172. 